\title{
O DIREITO FUNDAMENTAL À SAÚDE E AS DOENÇAS RARAS: CONSIDERAÇÕES ACERCA DO CONTROLE DE POLÍTICÁS PÚBLICAS PELO SUPREMO TRIBUNAL FEDERAL
}

\author{
Luciana Gaspar Melquíades Duarte* \\ Víctor Luna Vidal**
}

\section{RESUMO}

$\mathrm{O}$ artigo objetiva analisar a sindicabilidade judicial do direito fundamental à saúde no tocante aos pedidos de custeio estatal de tratamentos para doenças raras. A pesquisa propõe a investigação do núcleo essencial do direito à saúde e a análise das políticas públicas para pacientes com doenças raras no Brasil. Adota-se como arcabouço teórico o Pós-Positivismo Jurídico, representado por Dworkin (2002) e Alexy (2011). Sob a metodologia dedutiva, procedeu-se a uma pesquisa qualitativa. As investigações do trabalho conduzem à possibilidade de provisão judicial de pedidos de tratamentos não inseridos nas políticas públicas de saúde quando tutelar a vida e a dignidade.

Palavras-chave: Direito Fundamental à Saúde. Judicialização. Doenças Raras. Sistema Único de Saúde. Políticas Públicas de Saúde.

\section{THE FUNDAMENTAL RIGHT TO HEALTH AND RARE DESEASES: CONSIDERATIONS ABOUT THE CONTROL OF PUBLIC POLICIES BY THE FEDERAL SUPREME COURT}

\begin{abstract}
The article aims to analyze the judicialization of the fundamental right to health with regard to requests for state funding of rare diseases treatments. The research proposes to investigate the essential core of the right to health and to analyze public policies for rare disease patients in Brazil. It is adopted as theoretical framework the Legal Post-Positivism, represented by Dworkin (2002) and Alexy (2011). Under the deductive methodology, a qualitative research was carried out. This investigation lead to the possibility of judicial provision of requests for treatment not included in public health policies when protecting life and dignity.
\end{abstract}

Key-words: Fundamental Right to Health. Judicialization. Rare Diseases. National Health Service. Health Public Policies.

\footnotetext{
*Mestre e Doutora em Direito pela Universidade Federal de Minas Gerais. Professora Adjunta de Direito Constitucional e Administrativo da Universidade Federal de Juiz de Fora, Pesquisadora, Professora do Mestrado em Direito e Inovações da Faculdade de Direito da UFJF e ex-Procuradora do Município de Juiz de Fora. Endereço: Universidade Federal de Juiz de Fora, Faculdade de Direito, s/n, Cidade Universitária 36013-020 - Juiz de Fora, MG - Brasil. Endereço eletrônico: lg.melquiades@ uol.com.br

** Mestre em Direito pela Universidade Federal de Juiz de Fora. Bacharel em Direito pela mesma instituição. Advogado. Endereço: Rua Coronel Juvenal Pena, 10, Centro - 36180-000 - Rio Pomba, MG - Brasil. Endereço eletrônico: victorlunavidal@live.com
} 


\section{INTRODUÇÃO}

Neste trabalho, o fenômeno da judicialização da saúde é analisado com enfoque em um ponto específico da temática, qual seja, o afeito às enfermidades raras. Caracterizadas por baixos índices de prevalência e por limitadas opções de tratamentos disponibilizados pela rede pública de saúde, elas suscitam o debate no tocante à garantia da integralidade do Sistema Único de Saúde. Torna-se necessária a discussão, portanto, quanto ao tratamento judicial de tais questões, na medida em que os pedidos levados à apreciação em juízo geralmente estão vinculados a prestações de saúde que excedem o conteúdo das políticas públicas de saúde. Além disso, argumentos em torno do elevado custo dos tratamentos e da potencial violação ao princípio da igualdade justificam a análise minuciosa dos argumentos atinentes à esfera jurisprudencial.

Esta investigação tem como fundamento teórico o Pós-Positivismo jurídico, movimento jusfilosófico que tem como uma de suas principais contribuições a redefinição da relação entre Direito e Moral na contemporaneidade e os alicerces da dignidade humana na centralidade dos direitos fundamentais. De acordo com a proposta pós-positivista, nas abordagens de Alexy (2011) e de Dworkin (2002), as normas constitucionais são interpretadas sob a perspectiva de regras e princípios definidores do direito fundamental à saúde.

O trabalho visa alcançar objetivos específicos, como a revisão da literatura disponível a respeito do tema, o estudo dos marcos normativos relativos à saúde pública, a atenção às doenças raras no país e o levantamento da jurisprudência do Supremo Tribunal Federal. Os diversos elementos analisados conduzem à discussão dos critérios para a abordagem teórica e jurisprudencial das doenças raras.

\section{O PÓS-POSITIVISMO JURÍDICO E A SINDICABILIDADE JUDICIAL DOS DIREITOS FUNDAMENTAIS SOCIAIS}

Em meio às discussões promovidas nos campos da Teoria do Direito e do Direito Constitucional, o Pós-Positivismo Jurídico surgiu como uma tentativa de aperfeiçoamento do Positivismo Jurídico por meio da contenção do seu potencial de arbitrariedade. Em contraposição, por exemplo, ao Positivismo normativista de Kelsen (2006), em que o juiz elege volitiva e discricionariamente o significado que considera mais adequado para 
determinada norma, sob a ótica pós-positivista, os juízes, por não serem eleitos democraticamente, têm a legitimidade de suas decisões calcada na promoção da racionalização argumentativa.

Nesse contexto, a reformulação do modelo de normatividade constitucional póspositivista chancela o esforço teórico destinado à garantia da justiça material das decisões e da racionalização do discurso jurídico. O novo modelo científico é fundado em normas definidoras de direitos fundamentais, que tangenciam todo o ordenamento jurídico (ALEXY, 2011). Tais normas são originárias da proteção constitucional dos valores oriundos do debate democrático e da celebração de tratados internacionais de direitos humanos no período pósSegunda Guerra Mundial. Em Dworkin (2002), por exemplo, as normas jurídicas incorporam os valores comunitários utilizados na fundamentação principiológica das decisões judiciais, o que limita a discricionariedade na atuação judicial.

Proposta inicialmente por Dworkin (2002), a distinção entre regras e princípios tem o seu aprimoramento teórico em Alexy (2011). De acordo o jusfilósofo alemão, as espécies normativas são qualitativamente distintas. Assim, os princípios traduzem “[...] normas que ordenam que algo seja realizado na maior medida possível, dentro das possibilidades jurídicas e reais existentes" (ALEXY, 2011, p. 90). Correspondem a "mandados de otimização" (ALEXY, 2011, p. 90), que podem ser realizados, em maior ou menor medida, a depender das circunstâncias fáticas e jurídicas do caso concreto. Já as regras “[...] são normas que apenas podem ser cumpridas ou não; se uma regra for válida, dever-se-á fazer exatamente o que ela exige, nem mais nem menos. Portanto, as regras contêm determinações no âmbito do fática e juridicamente possível” (ALEXY, 2011, p. 91), sendo aplicadas de acordo com o procedimento da subsunção.

As colisões entre princípios e os conflitos entre regras são solucionados de forma distinta. O conflito entre regras soluciona-se pelo reconhecimento da invalidade de uma das normas ou pela verificação da existência de uma cláusula de exceção. Desse modo, são empregados os critérios para a solução de antinomias aparentes, a saber, 1) lex posterior derogat legi priori, 2) lex specialis derogat legi generali e 3) lex superior derogat legi inferiori. Já as colisões entre princípios analisam a relação de precedência dos enunciados normativos de acordo com as condições específicas do caso narrado. Tem-se a dimensão do peso, em que inexiste a precedência geral de um princípio sobre outro (ALEXY, 2011). A ponderação resulta na formulação de uma regra para o caso concreto. 
Nesse contexto, destaca-se o emprego da máxima da proporcionalidade ${ }^{1 .}$ Como procedimento analítico, ela desdobra-se em 3 submáximas, quais sejam, 1) adequação, que envolve o juízo de determinação da relação entre meios e fins, 2) necessidade, definida pela eleição do meio que potencialmente afeta o outro princípio colidente na menor medida possível e 3) proporcionalidade em sentido estrito, utilizada para mensurar, de forma argumentativa e racional, a relevância da interferência de um princípio sobre outro por meio da comparação entre os valores tutelados no contexto fático.

O pluralismo resultante do debate constituinte resultou na incorporação de direitos sociais no plano constitucional. No tocante aos direitos fundamentais sociais, a preocupação do constituinte não se limitou a prevê-los, como também procurou traçar parâmetros para a sua concretização. Embora o Estado brasileiro não tenha se constituído historicamente sob a perspectiva do Welfare State, iniciativas no sentido de proteger os direitos sociais foram concretizadas naquele momento histórico (CIARLINI, 2013, p. 27). Exemplificativamente, o direito à saúde apresenta disposições específicas para a sua concretização, como a previsão de metas a serem alcançadas e normas organizatórias do sistema público.

Pelo conceito constitucional de saúde, tem-se uma noção alargada de bem-estar, o que envolve, conforme Dallari (2008, p.11-12), além da ausência de doenças, condições de vida e de organização social dos indivíduos. Essa concepção advém do período do pós-Segunda Guerra Mundial, em que foi criada, em 1946, a Organização Mundial de Saúde (WHO, 1946).

Com a promulgação da Constituição (BRASIL, 1988), a tutela da saúde, conforme o artigo 197, adquiriu status de relevância pública, o que afasta qualquer discussão tendente à minimização da sua essencialidade e do dever estatal em promovê-la (DALLARI; MAGGIO, 2017, p. 63-64). Tal dever é traduzido na organização do Sistema Único de Saúde - SUS, previsto pelo artigo 196 da Constituição (BRASIL, 1988).

No Brasil, as insatisfações da população no tocante à eficácia ao direito fundamental à saúde conduzem à judicialização das políticas públicas ou ao fenômeno da justiciabilidade. Definido como "exigibilidade judicial" (TOLEDO, 2017a, p 278), o termo qualifica a crescente invocação do Poder Judiciário para a efetivação dos direitos, e, em especial, os sociais. Vinculada à justiciabililidade, a discussão quanto às competências dos Poderes

\footnotetext{
${ }^{1}$ De acordo com Toledo (2017b), a expressão advém do termo em alemão "Verhältnismässigkeitsgrundsatz", traduzido adequadamente por "máxima da proporcionalidade". Apresentando a estrutura de regra, a máxima da proporcionalidade não comporta aplicação gradual, característica dos princípios. Assim, ela não designa uma norma jurídica propriamente dita, embora a sua aplicação seja idêntica ao procedimento das regras. Tal razão justifica o emprego da expressão "máxima".
} 
Públicos na formulação e na execução de políticas públicas conduz, a depender da situação avaliada e do ponto de vista do jurista, à denominação de ativismo judicial, quando a atuação excede os limites previstos pelo princípio da separação dos poderes, ou ao reconhecimento do exercício regular da função de controle dos demais poderes, quando os direitos são protegidos de forma insuficiente ou sofrem limitações excessivas (TOLEDO, 2017a).

Tais constatações advêm da dupla função atribuída ao princípio formal da separação dos poderes. Embora ele possa ser avaliado sob a perspectiva de limitação do exercício das competências atribuíveis a cada poder, também é possível concebê-lo a partir da ótica de controle recíproco do exercício dos deveres constitucionais, quando se impõe a investigação do núcleo essencial do direito à saúde, que retoma a tutela da dignidade. Conforme discutido, o referido direito abarca não somente a ideia de ausência de doença, ou a sua redução a um mínimo vital. Contempla-se, portanto, uma perspectiva qualitativa, que envolve a promoção do bem-estar, concretizado por meio de prestações mínimas para a fruição do direito em condições dignas.

Pode-se pensar que a definição do núcleo do direito corresponde à prestação da atenção básica de saúde. Estando a saúde vinculada essencialmente à vida, pressuposto para o gozo dos demais direitos fundamentais, a proposta acima carece de aprimoramento: a depender da situação de cada pessoa, a proteção da vida pode exigir desde prestações de saúde de baixa complexidade até prestações complexas.

São também criticáveis propostas que limitam o núcleo essencial a prestações de urgência, conforme defendido por Sarlet e Figueiredo (2010). As prestações de urgência, embora sejam consideradas de extrema relevância, correspondem a apenas parte do conjunto de prestações de saúde destinadas à preservação da vida. Restringir a proteção da vida à atenção de urgência é critério insuficiente por três principais razões. Primeiro, porque corresponde a parâmetro cruel, na medida em que requer a piora na condição de saúde do paciente para o atendimento. Segundo, tal medida limita as chances de sucesso do tratamento, bem como potencialmente encarece as despesas com o tratamento de urgência (DUARTE, 2013). Terceiro, porque o regime constitucional em matéria de saúde impõe ao Estado a ênfase nas atividades de caráter preventivo, conforme definido pelo artigo 198, II, da Constituição (BRASIL, 1988).

Outro parâmetro é defendido por Barcellos (2010). Para a autora, o núcleo do direito à saúde vincula-se ao cumprimento de quatro prioridades previstas pela Constituição (BRASIL, 
1988): 1) saneamento básico (arts. 23, IX; 198, II; e 200 IV); 2) atendimento materno-infantil (art. 227, § $1^{\circ}$, I); 3) medicina preventiva (art. 198, II) e 4) prevenção epidemiológica (art. 200, II). A proposta é referendada pelas disposições constitucionais. No entanto, ela tutela a vida e a saúde apenas parcialmente, haja vista a possível exclusão, por exemplo, de prestações de elevado custo indispensáveis à preservação da vida.

Ante o impasse teórico examinado, Duarte (2011) identifica o núcleo essencial do direito à saúde a partir da perspectiva da integralidade do direito. Destarte, utilizou os termos demandas de saúde de primeira e de segunda necessidade para demarcar, respectivamente, as prestações estatais destinadas à proteção da vida, e as prestações não diretamente relacionadas à manutenção da mesma, estando associadas à qualidade de vida. Consubstanciado em uma regra, o núcleo essencial do direito à saúde consagra direitos definitivos, não sendo cabíveis argumentos dirigidos ao seu afastamento, como a higidez orçamentária. Por seu turno, o caráter principiológico das demandas de saúde de segunda necessidade suscita a colisão com os demais princípios.

Apesar de superar os problemas da maior parte dos critérios sustentados pela doutrina, a proposta inicial de Duarte (2011) sofreu aprimoramento. Nota-se que a limitação do núcleo essencial à vida é insuficiente diante do mandamento constitucional de efetivação da dignidade humana. Por conseguinte, a vida, apartada de condições de saúde minimamente dignas, não observa os preceitos constitucionais de forma integral. A definição de quais prestações são de elevada essencialidade para a vida digna é tarefa a cargo da argumentação.

A revisão do conceito do núcleo essencial do direito a saúde apresenta-se imprescindível para o enfrentamento da problemática objeto deste trabalho, qual seja, a judicialização de tratamentos de doenças raras, considerado o fato de que, em parte significativa das situações enfrentadas pelo Poder Judiciário, a tutela da vida torna-se insuficiente ao reconhecimento do ser humano como sujeito dotado de dignidade. Desse modo, o próximo item analisa as políticas públicas de saúde para doenças raras no país.

\section{POLÍTICAS PÚBLICAS DE SAÚDE E DOENÇAS RARAS}

Segundo Aith et al (2014, p. 18), a compreensão dos desafios à efetivação dos princípios da universalidade e da integralidade tem como indicador a forma como são tratados os portadores de doenças raras no país. Considerando fatores como a baixa prevalência das 
doenças e o alto custo dos produtos e serviços de saúde, quando disponíveis, as noções de integralidade e de atendimento universal são colocadas em xeque (AITH et al, 2014, p. 18).

A temática ora explorada requer o estudo de conceitos específicos. O entendimento, por exemplo, do que são as doenças raras varia entre os países e entidades públicas. No Brasil, o Ministério da Saúde tem como raras um conjunto de doenças que apresenta "uma ampla diversidade de sinais e sintomas", que "variam não só de doença para doença, mas também de pessoa para pessoa acometida pela mesma condição" (BRASIL, 2019).

De acordo com o Ministério da Saúde, tais enfermidades são classificadas em degenerativas e proliferativas, sendo que $80 \%$ (oitenta por cento) delas advêm de causas genéticas, enquanto o restante tem como origem, entre outros fatores, elementos ambientais, infecciosos e imunológicos (BRASIL, 2019). Apesar da diversidade de condições específicas, o conjunto mais significativo delas tem como elemento comum a sua caracterização como doenças crônicas e debilitantes.

As políticas públicas destinadas aos cuidados com doenças raras têm início nos Estados Unidos, com o Orphan Drug Act (U.S. FOOD AND DRUG ADMINISTRATION, 2019). Diante do limitado potencial de exploração lucrativa dos medicamentos órfãos, isto é, os medicamentos indicados para o tratamento de doenças raras, a política estadunidense teve como objetivo a concessão pelo Estado de incentivos econômicos e técnicos à indústria farmacêutica. Marcos normativos semelhantes foram implementados em outros países. Na Europa, a iniciativa da Comissão Europeia originou o Regulamento $\mathrm{n}^{\circ} 141$ (UNIÃO EUROPEIA, 2000), conferindo novas competências à Agência Europeia do Medicamento e delimitando critérios para o recebimento dos incentivos públicos à pesquisa e ao desenvolvimento de medicamentos órfãos (SEPODES; MOTA-FILIPE, 2013, p. 59).

Os marcos regulatórios acima determinam os critérios para a definição de doenças raras. De acordo com Huyard (2009), o enquadramento dessa categoria de enfermidades vincula-se aos critérios econômicos e populacionais previstos nas legislações de fomento, não havendo, portanto, aspectos médicos ou científicos que tratem das doenças raras de forma única. Retomando os marcos regulatórios indicados, são consideradas raras, nos Estados Unidos, o que justifica a inclusão dos laboratórios farmacêuticos nos programas 
governamentais de incentivos, as doenças que atingem até 200.000 pessoas $^{2}$. Nos países da União Europeia, o critério é aferido proporcionalmente à população, sendo beneficiadas as pesquisas para o tratamento de doenças que atingem até 1 pessoa por grupo de 2.000 (EURORDIS, 2019). O indicador brasileiro está previsto no artigo $3^{\circ}$ da Portaria $n^{\circ} 199$ (BRASIL, 2014a), que adota a proporção de 1,3 pessoas a cada 2000 indivíduos.

No Brasil, não há programas de incentivo à produção de medicamentos órfãos. No entanto, iniciativas têm sido conduzidas no sentido de ampliação da oferta de medicamentos e de cuidados específicos destinados aos portadores de doenças raras pelo SUS.

De acordo com Aith et al (2014, p. 23), somente no período mais recente o Brasil adotou estratégias específicas dirigidas ao cuidado com doenças raras. No tocante à assistência farmacêutica, a Portaria $\mathrm{n}^{\mathbf{0}} 204$ (BRASIL, 2007a), ao regulamentar o financiamento do SUS, delimitou os níveis de atuação do poder público na assistência farmacêutica. Assim, foram instituídos os componentes básico e estratégico, cujos escopos são, respectivamente, o fornecimento de produtos farmacêuticos voltados à atenção básica e o financiamento de políticas estratégicas de saúde, como o cuidado com doenças endêmicas, AIDS e enfermidades causadas por agentes imunobiológicos. O componente especializado, referente aos medicamentos de dispensação excepcional, ficou sujeito à regulamentação específica (AITH et al, 2014, p. 23), sendo aprovado pela Portaria no 2.981 (BRASIL, 2009a).

De acordo com a Portaria $n^{\circ} 2.981$ (BRASIL, 2009a), os medicamentos de dispensação excepcional são distribuídos em consonância com a estratégia de acesso integral, o que deve observar os Protocolos Clínicos e Diretrizes Farmacêuticas - PCDT's - definidos pelo Ministério da Saúde e aplicados na esfera ambulatorial (AITH et al, 2014, p. 23). As diretrizes determinadas pelo Ministério da Saúde até aquele momento, embora permitissem a incorporação de tratamentos de saúde destinados a doenças raras, não dirigiram atenção específica ao setor.

Em 2009, foi lançada a Política Nacional de Atenção Integral em Genética Clínica PNAIGC, que teve nos portadores de doenças raras um dos principais grupos beneficiados. A PNAIGC teve como objetivo promover a articulação dos níveis de gestão do sistema público de saúde para a atenção das doenças de origem genética.

\footnotetext{
${ }^{2}$ Outro critério utilizado, mas de fundamento econômico, refere-se à comprovação de que o custo com Pesquisa e Desenvolvimento (P\&D) para determinado produto farmacêutico não é recuperável (U.S. FOOD AND DRUG ADMINISTRATION, 2019).
} 
As discussões em torno da incorporação de tecnologias e de instrumentos de proteção da saúde conduziram à promulgação da Lei $n^{\circ} 12.401$ (BRASIL, 2011b), que alterou a Lei ${ }^{\circ}$ 8.080 (BRASIL, 1990), e instituiu a Comissão Nacional de Incorporação de Tecnologias no Sistema Único de Saúde - CONITEC. Segundo Aith et al (2014, p. 16), a Lei 12.401 (BRASIL, 2011b), visa garantir a transparência e a participação popular no processo de incorporação tecnológica do SUS, mediante a avaliação do processo de incorporação de tecnologias no âmbito do sistema público por pacientes, gestores e profissionais de saúde.

Tendo o apoio do Departamento de Gestão e Incorporação de Tecnologias em Saúde DGITS, a CONITEC assessora o Ministério da Saúde no processo de incorporação de tecnologias ao SUS, além de atuar na constituição e ou alteração dos PCDT's (BRASIL, 2015a). Os PCDT's são utilizados como referências para o atendimento dos pacientes do SUS, vinculando a atuação do sistema público de saúde nos três níveis federativos.

A incorporação de medicamentos pelo SUS é também regida pelo Decreto $\mathrm{n}^{\mathrm{o}} 7.508$ (BRASIL, 2011a), que trata de algumas disposições da Lei no 8.080 (BRASIL, 1990). Sob o ponto de vista da organização dos medicamentos e dos serviços fornecidos pelo SUS, o decreto prevê o estabelecimento da Rede Nacional de Serviços de Saúde - RENASES - e da Relação Nacional de Medicamentos Essenciais - RENAME, listas oficiais que determinam a previsão dos serviços e medicamentos contemplados pelo SUS.

Apesar das ações desenvolvidas no âmbito do SUS promoverem a ampliação do princípio da integralidade, a atenção específica aos portadores de doenças raras somente concretizou-se com a Portaria $\mathrm{n}^{\circ} 199$ (BRASIL, 2014a). Tal portaria caracteriza o fenômeno da normatização das políticas públicas, correspondente à instituição de deveres jurídicos a cargo do Estado e à ampliação do controle social da atuação estatal (AITH, 2014, p. 8).

A Política de Doenças Raras observa objetivos gerais, conforme o prevê o artigo $4^{\circ}$ da Portaria n 199 (BRASIL, 2014a). Assim, são estipuladas ações com o escopo de redução da mortalidade, da morbimortalidade e das manifestações secundárias, além de promoção da qualidade de vida dos pacientes, por meio de um conjunto de ações voltadas à prevenção, ao diagnóstico, ao tratamento e ao fornecimento de cuidados paliativos (BRASIL, 2014a).

Definidos no artigo $5^{\circ}$ (BRASIL, 2014a), os objetivos específicos destinam-se à efetivação dos princípios da integralidade, da universalidade e da equidade na prestação dos serviços de saúde, o que requer a atuação conjunta de todos os entes federativos. A melhoria na atenção aos pacientes é traduzida pelo estímulo à capacitação dos profissionais de saúde e 
à oferta de serviços destinados à habilitação e à reabilitação das pessoas, tendo como objetivo a inclusão social dos pacientes e o desenvolvimento de sua autonomia (BRASIL, 2014a).

As políticas públicas de atenção aos portadores de doenças raras apresentam alguns indicadores relativos à capacidade de atendimento dos pacientes e à ampliação do princípio da integralidade do SUS. Atualmente, existem 8 centros reconhecidos pelo Ministério da Saúde como habilitados e especializados na atenção aos pacientes (BRASIL, 2019). No tocante aos Protocolos Clínicos e Diretrizes Farmacêuticas direcionados à matéria, houve um aumento de 35 (BRASIL, 2015a) para 40 (BRASIL, 2019) protocolos.

Apesar dos avanços, há de se reconhecer que, por mais que o Estado se esforce na ampliação de políticas públicas que objetivem o atendimento das necessidades de toda a população, a sua atuação ainda apresenta-se insuficiente sob a perspectiva da complexidade que envolve o direito à saúde, mantendo-se, pois, o combustível para o fenômeno da judicialização.

No tocante às doenças raras, Dallari (2015, p. 259) adverte para um outro problema: o limitado número de potenciais participantes dos testes clínicos dos novos produtos farmacêuticos torna necessária a relativização dos parâmetros de segurança e eficácia dos fármacos, o que é feito, conforme discutido, pela concessão de incentivos à criação de drogas órfãs.

Os conflitos éticos, econômicos e administrativos no tocante à dispensação de tratamentos para doenças raras pela via judicial suscita a reflexão quanto à propositura de critérios racionais e harmônicos com as disposições constitucionais. De modo a apreciar como os pedidos de tratamentos de doenças raras têm sido enfrentados na esfera judicial, o item seguinte investiga as decisões do Supremo Tribunal Federal.

\section{O SUPREMO TRIBUNAL FEDERAL E A JUDICIALIZAÇÃO DOS TRATAMENTOS DE DOENÇAS RARAS}

De modo a promover a pesquisa do tratamento judicial dos pedidos de tratamentos de doenças raras, acessou-se o portal eletrônico do Supremo Tribunal Federal no dia 19 de dezembro de 2018. Em sequência, foram selecionados os itens jurisprudência e pesquisa livre. Nesse campo, foram digitados os termos de busca "doença e rara". Destacadas as chaves de busca, selecionou-se a caixa "pesquisar". 
A pesquisa apresentou os seguintes resultados: 5 (cinco) acórdãos, nenhuma súmula, nenhuma súmula vinculante, 35 (trinta e cinco) decisões monocráticas, 31 (trinta e uma) decisões da presidência, nenhuma questão de ordem, nenhuma repercussão geral. De todos os conteúdos apresentados, somente 33 deles têm pertinência com o presente objeto de estudo. Os dados coletados foram organizados na tabela abaixo indicada:

Tabela 4: resumo quantitativo dos julgados do Supremo Tribunal Federal quanto aos termos de pesquisa "doença" e "rara"

\begin{tabular}{lllllll}
\hline $\begin{array}{l}\text { Tipo de } \\
\text { documento } \\
\text { pesquisado }\end{array}$ & $\begin{array}{l}\text { Total de } \\
\text { documento } \\
\text { retornados }\end{array}$ & $\begin{array}{l}\text { Quantidad } \\
\text { e de } \\
\text { documento } \\
\mathrm{s} \\
\text { excluídos }\end{array}$ & $\begin{array}{l}\text { Quantidad } \\
\text { e de } \\
\text { documento } \\
\text { s utilizados }\end{array}$ & $\begin{array}{l}\text { Quantidad } \\
\text { e de } \\
\text { deferiment } \\
\text { os }\end{array}$ & $\begin{array}{l}\text { Quantidade } \\
\text { de } \\
\text { indeferimen } \\
\text { tos }\end{array}$ & $\begin{array}{l}\text { Mérito } \\
\text { não } \\
\text { apreciado }\end{array}$ \\
\hline Acórdão & 5 & 1 & 4 & 2 & 0 & 2 \\
\hline $\begin{array}{l}\text { Decisão } \\
\text { monocráti } \\
\text { ca }\end{array}$ & 35 & 26 & 9 & 0 & 0 & 9 \\
\hline $\begin{array}{l}\text { Decisão da } \\
\text { presidênci }\end{array}$ & 31 & 11 & 20 & 20 & 0 & 0 \\
a & & & & & \\
\hline Totais & 71 & 38 & 33 & 22 & 0 & 11 \\
\hline
\end{tabular}

Fonte: Elaborado pelos autores

As decisões pesquisadas revelam o posicionamento do Supremo Tribunal Federal no período compreendido entre os anos de 1997 e 2018. A primeira decisão encontrada foi publicada em 13 de fevereiro de 1997 e a última em 26 de setembro de 2018. As decisões avaliadas sinalizam uma tendência amplamente favorável ao deferimento dos tratamentos.

No período compreendido entre 13 de fevereiro de 1997 e 12 de fevereiro de 2001, ressalvadas as decisões que não tiveram o mérito apreciado, todos os julgados foram favoráveis à concessão das medidas pleiteadas. O conjunto de decisões característico desse período pautou-se pela utilização de argumentos em defesa da vida e da saúde dos pacientes.

A partir do recurso extraordinário no 248304 (BRASIL, 2001b), outros argumentos foram suscitados nas decisões. Embora tenha sido reconhecido o caráter programático das normas de direito fundamental relativas à saúde, a decisão assentou que isso não pode ser convertido em "[...] promessa constitucional inconsequente, sob pena de o Poder Público, fraudando justas expectativas nele depositadas pela coletividade, substituir, de maneira 
ilegítima, o cumprimento de seu impostergável dever, por um gesto irresponsável de infidelidade [...]" (BRASIL, 2001b) àquilo que determina a Constituição (BRASIL, 1988). O argumento esteve presente também nos recursos extraordinários nº 198265 (BRASIL, 2001a) e 297276 (BRASIL, 2004).

Outro argumento recorrente foi a investigação dos recursos financeiros dos pacientes e de suas famílias para o custeio dos procedimentos de saúde, destacando-se 12 decisões ${ }^{3}$. Sendo a saúde um direito de natureza social e, portanto, ostentando caráter redistributivo, a capacidade de custeio dos tratamentos pelos sujeitos interessados foi um parâmetro recorrente nas decisões. Advém da necessidade de tratamento igualitário o respeito à dimensão material do princípio. De acordo com as decisões elencadas, torna-se incompatível com a ordem jurídica a realocação de recursos para o custeio de procedimentos não contemplados pelo SUS àqueles que podem arcar com os custos dos tratamentos sem que sejam comprometidos os demais recursos financeiros aptos a garantir sua dignidade. Tal concepção decorre do reconhecimento da universalidade do direito à saúde como um princípio, isto é, um mandamento de otimização sujeito a restrições de acordo as circunstâncias fáticas e jurídicas eventualmente analisadas.

A inadequação dos tratamentos disponibilizados pela rede pública e/ou a submissão sem sucesso a eles pelos pacientes foram elementos mencionados em 17 decisões ${ }^{4}$. Com exceção do recurso extraordinário no 297276 (BRASIL, 2004), em que o mérito da causa não foi apreciado, todos os julgados elencados tiveram os pedidos deferidos. Para tanto, foi considerada a consulta aos tratamentos disponíveis no SUS. O insucesso das medidas prescritas ao paciente pelo SUS resultaram na concessão dos tratamentos pedidos. De modo semelhante, a indicação por profisssionais da saúde e instituições especializadas nas enfermidades, quanto à ineficácia das prestações contempladas pelo SUS ou à existência de

\footnotetext{
${ }^{3}$ São as decisões: agravo em recurso extraordinário $n^{\circ} 952389$ (BRASIL, 2016), medida cautelar na petição ${ }^{\circ}$ 1246 (BRASIL, 1997), suspensões de segurança ${ }^{\circ} 4316$ (BRASIL, 2011d), $\mathrm{n}^{\circ} 4304$ (BRASIL, 2011c), $\mathrm{n}^{\circ} 3852$ (BRASIL, 2010b) e $\mathrm{n}^{\circ} 3205$ (BRASIL, 2007b), suspensão de liminar $\mathrm{n}^{\circ} 256$ (BRASIL, 2010a), suspensões de tutela antecipada $\mathrm{n}^{\circ} 361$ (BRASIL, 2009f), $\mathrm{n}^{\circ}$ 175/(BRASIL, 2009c), $\mathrm{n}^{\circ} 277$ (BRASIL, 2008b) e recursos extraordinários no 297276 (BRASIL, 2004) e nº 248304 (BRASIL, 2001b).

${ }^{4}$ São as decisões: agravo regimental na suspensão de liminar $n^{\circ} 558$ (BRASIL, 2017a), agravo regimental na suspensão de tutela antecipada $\mathrm{n}^{\circ} 761$ (BRASIL, 2014b), medida cautelar na suspensão de segurança $\mathrm{n}^{\circ} 5192$ (BRASIL, 2017b), medida cautelar na suspensão de tutela antecipada $n^{\circ} 24$ (BRASIL, 2018a), suspensão de liminar $\mathrm{n}^{\circ} 319$ (BRASIL, 2009b), suspensões de tutela antecipada $\mathrm{n}^{\circ}$ 761(BRASIL, 2015b), n ${ }^{\circ} 175$ (BRASIL, 2009c), $n^{\circ} 198$ (BRASIL, 2008a), n 361 (BRASIL, 2009f), nº 244 (BRASIL, 2009e) e $n^{\circ} 36$ (BRASIL, 2005), suspensão de tutela provisória $n^{\circ} 24$ (BRASIL, 2018b), suspensões de segurança $\mathrm{n}^{\circ} 4316$ (BRASIL, 2011d), $\mathrm{n}^{\circ}$ 4304 (BRASIL, 2011c), no 3852 (BRASIL, 2010b) e no 3205 (BRASIL, 2007b) e recurso extraordinário n ${ }^{\circ}$ 297276 (BRASIL, 2004).
} 
tratamentos e medicamentos de saúde produzidos ou prestados de forma exclusiva entes privados, no Brasil e no exterior, constituíram argumento em favor da concessão dos pedidos.

Associado a tal parâmetro, a gravidade das potenciais lesões à saúde e à vida dos pacientes foi avaliada pelo nível de afetação da dignidade dos pacientes. Assim, a tese do dano inverso foi recorrente nas decisões. Por esse raciocínio, a não concessão das medidas pleiteadas foi considerada como opção mais gravosa aos requerentes, na medida em que a espera poderia resultar em morte ou no agravamento do quadro clínico.

Tendo como escopo o controle da eficácia e da segurança dos medicamentos e procedimentos de saúde no país, a Agência Nacional de Vigilância Sanitária - ANVISA - foi consultada quanto à existência do registro dos medicamentos solicitados. A competência da agência reguladora para o controle de produtos farmacêuticos advém do artigo $7^{\circ}$ da Lei $n^{\circ}$ 9.782 (BRASIL, 1999). Por seu turno, o artigo 19-T da Lei no 8.080 (BRASIL, 1990) veda o custeio pelo SUS de prestações de saúde de caráter experimental ou não autorizadas pela ANVISA. Nesse sentido, foram identificadas 12 decisões $^{5}$ que verificaram se havia registro do tratamento solicitado perante a agência sanitária. As decisões supramencionadas consideraram a existência (ou não) de registro de medicamentos perante a agência oficial sanitária. Salvo pela suspensão de tutela antecipada $n^{\circ} 244$ (BRASIL, 2009d), em que o mérito não foi apreciado, as decisões foram favoráveis à concessão dos tratamentos.

Alguns argumentos foram utilizados para justificar tais decisões. A suspensão de liminar em agravo regimental $n^{\circ} 558$ (BRASIL, 2017), por exemplo, fundamentou-se na prévia comercialização do produto nos EUA. Havendo apenas tratamentos paliativos disponíveis pelo SUS para hemoglobinúria paroxística noturna, enfermidade objeto da decisão em análise, e requerendo esse procedimento intervenções consideravelmente invasivas, como a transfusão de sangue, foi considerado o elevado nível de essencialidade da prestação pleiteada para a manutenção da vida com dignidade da paciente. A decisão considerou ainda o potencial agravamento do estado de saúde da paciente, haja vista o risco de desencadeamento de "outras enfermidades, como anemia, trombose, insuficiência renal crônica, hipertensão pulmonar, insuficiência hepática e AVC - acidente vascular cerebral” (BRASIL, 2017). Em

\footnotetext{
${ }^{5}$ São as decisões: agravo regimental de suspensão de liminar $n^{\circ} 558$ (BRASIL, 2017a), agravo regimental na suspensão de tutela antecipada $\mathrm{n}^{\circ} 761$ (BRASIL, 2014b), medida cautelar na suspensão de segurança $\mathrm{n}^{\circ} 5192$ (BRASIL, 2017b), suspensão de liminar $n^{\circ} 319$ (BRASIL, 2009b), suspensão de segurança $n^{\circ} 4316$ (BRASIL, 2011d) e $\mathrm{n}^{\circ} 4304$ (BRASIL, 2011c) e suspensões de tutela antecipada $\mathrm{n}^{\circ} 761$ (BRASIL, 2014b), $\mathrm{n}^{\circ} 361$ (BRASIL, 2009f), $\mathrm{n}^{\circ} 244$ (BRASIL, 2009d), $\mathrm{n}^{\circ} 175$ (BRASIL, 2009), $\mathrm{n}^{\circ} 198$ (BRASIL, 2008a) e $\mathrm{n}^{\circ} 244$ (BRASIL, 2009e).
} 
se tratando do único tratamento adequado existente, foi reconhecida a sua imprescindibilidade.

Todas as decisões relativas ao fornecimento do medicamento Soliris (eculizumab) para o tratamento de hemoglobinúria paroxística noturna foram favoráveis aos pedidos. Reconhecendo a inexistência de outras medidas mais adequadas, a lesividade dos tratamentos alternativos fornecidos pelo SUS e a comercialização do medicamento em outros países, as decisões - suspensão de tutela antecipada em agravo regimental de $\mathrm{n}^{\circ} 761$ (BRASIL, 2015b), suspensão de tutela antecipada $n^{\circ} 761$ (BRASIL, 2014b) suspensões de segurança $n^{\circ} 4316$ (BRASIL,2011d) e no 4304 (BRASIL, 2011c) - foram baseadas em argumentos semelhantes.

Embora a suspensão de segurança em medida cautelar no 5192 (BRASIL, 2017) tenha apresentado razões semelhantes àquelas das decisões anteriores, algumas peculiaridades devem ser observadas. Atingida paciente menor de idade por atrofia muscular espinhal tipo 1, procedeu-se à alegação, com base na avaliação do médico que acompanhava a paciente, de que o fornecimento do medicamento Spinraza (nusinersen) seria o tratamento mais adequado para a doença, o que poderia evitar a ocorrência de resultados mais graves ao desenvolvimento psicomotor e à vida da paciente. Embora o argumento utilizado pela postulante tenha tido como base a indicação de profissional especializado na área, a decisão não considerou alguns parâmetros indicados nas demais decisões, como o posicionamento de outros profissionais ou instituições quanto eficácia e à segurança do tratamento ou o reconhecimento da confiabilidade do mesmo por entidades públicas de outros países.

Por fim, o tribunal foi favorável à concessão dos tratamentos indicados nas suspensões de tutela antecipada de $n^{\circ} 361$ (BRASIL, 2009f), 175 (BRASIL, 2009c), 244 (BRASIL, 2009e), 198 (BRASIL, 2008a) e na suspensão de liminar no 319 (BRASIL, 2009b) em razão da existência de registro da ANVISA, o que resulta na avaliação positiva do controle da segurança e da eficácia dos medicamentos.

\subsection{Análise crítica dos parâmetros de decisão em matéria de doenças raras}

As decisões analisadas no item anterior revelam o emprego de critérios decisórios. A garantia dos direitos à vida e à saúde foram indicados pelos STF como elementos norteadores do ordenamento jurídico nacional, o que se considera adequado, em vista da pertença dessas 
prestações ao núcleo essencial do direito à saúde, em que a vinculação estatal é absoluta, caracterizando, portanto, como indevida a omissão que ensejou a intervenção judicial.

Conforme sustentado por Alexy (2011), a existência de princípios formais é responsável por fundamentar os argumentos relacionados aos princípios materiais representativos dos direitos fundamentais. Embora haja uma precedência prima facie de que o Poder Judiciário observe as decisões tomadas no âmbito das políticas públicas definidas pelos Poderes Legislativo e Executivo, o que consubstancia os princípios da separação de poderes e da democracia, tais comandos não são, justamente em virtude de sua natureza principiológica, absolutos. A tensão característica da colisão entre princípios enuncia que, diante da omissão ou da intervenção excessivas perpetradas pelo Estado em matéria de direitos fundamentais, a atuação do Poder Judiciário manifesta-se não pela noção de "ativismo judicial", mas pelo cumprimento do seu papel constitucional de reequilíbrio da ordem jurídica.

A tensão entre os princípios mencionados caracteriza-se também pela observância, num primeiro momento, da existência de registro do medicamento perante a ANVISA, entidade responsável por atestar a segurança e a eficácia de medicamentos e demais produtos de saúde no país. O registro de medicamento na agência, desacompanhado da incorporação do tratamento pela rede pública, suscita um debate quanto à distinção dos cidadãos com base na capacidade econômica. Se a comercialização de determinado produto é autorizada no Brasil, a sua não incorporação pelo SUS obstaculiza o acesso dos pacientes mais pobres a prestações que podem significar a sua sobrevivência ou a garantia de condições mínimas de dignidade para a fruição dos direitos fundamentais. Portanto, adequada se revela a ordem judicial de dispensação do aludido fármaco pelo Estado em casos deste jaez.

Por seu turno, a inexistência de registro perante a ANVISA não significa que a prestação de saúde pleiteada não possa ser atendida. Dadas as limitações relacionadas às pesquisas em matéria de doenças raras, devem ser relativizados os parâmetros de segurança e eficácia no caso dos tratamentos órfãos. Em situações em que a gravidade das doenças pode resultar em sérios prejuízos à vida e à saúde das pessoas, a utilização de tais tratamentos corresponde à única esperança de pacientes.

Deve-se recordar que, em matéria de medicamentos para doenças raras, a relativização dos parâmetros de segurança e confiabilidade dos medicamentos repercutem na forma como são promovidas as decisões. Como os parâmetros para o desenvolvimento dos medicamentos órfãos não são idênticos àqueles destinados ao tratamento de grupos 
populacionais mais expressivos, não pode o julgador decidir a demanda com base nos critérios rigidamente definidos para a pesquisa e o desenvolvimento de medicamentos comuns.

Nesse contexto, deve-se admitir que os sujeitos envolvidos no processo de decisão quanto ao acesso de medicamentos órfãos tendem a "aceitar maiores riscos ou efeitos colaterais" (DALLARI, 2015, p. 260). Assim, tratamentos ou medicamentos não registrados na ANVISA, mas comercializados e registrados em países outros, podem ser dispensados, diante da ausência de alternativas, a pacientes portadores de doenças raras, inclusive pela via judicial.

Outra polêmica afeita à problemática desta pesquisa diz respeito ao corriqueiro elevado custo das prestações de saúde referentes a doenças raras. Registre-se, contudo, que,m entre o potencial risco de lesão ao orçamento público, oriundo da efetivação de prestações de saúde de elevado custo e da destinação de esforços no sentido de garantir a vida e a dignidade das pessoas, a tutela da saúde dos pacientes assume maior peso do que os argumentos contrários à efetivação dos direitos fundamentais.

Para o assecuramento dos direitos subjetivos violados pela insuficiência de políticas públicas, a judicialização individual apresenta-se, muitas vezes, como a última esperança do cidadão. De acordo com a proposta pós-positivista de leitura do ordenamento jurídico e de seus preceitos essenciais, a centralidade dos direitos fundamentais opera a proteção de interesses tanto individuais como coletivos. A submissão ao exercício ponderativo proposto por Alexy (2011) não permite que o julgador adote decisões abstrata e previamente determinadas em favor de um polo de interesse ou de outro. Desconsiderar os argumentos envolvidos no caso concreto significa não somente a omissão do julgador na condução do seu dever constitucional de apreciação das provas e dos argumentos invocados, o que é protegido pelo artigo $5^{\circ}$, inciso XXXV, da Constituição (BRASIL, 1988), mas o despreparo para lidar com situações de tensão entre as dimensões coletiva e individual dos direitos fundamentais.

A concepção de que o caminho a ser trilhado para a tutela dos direitos fundamentais, e em especial o direito à saúde, é o da tutela coletiva, embora pareça adequado sob a perspectiva da efetivação da igualdade e da racionalização dos recursos financeiros estatais, não são sustentáveis ante o previamente mencionado princípio da inafastabilidade da tutela jurisdicional. Conforme destacado por Sarlet (2011), conceber os direitos sociais como 
direitos tão somente coletivos é um equívoco na interpretação dos direitos fundamentais. Desse modo, deve-se admitir que os direitos também podem ser mensurados individualmente.

No mesmo sentido, Olsen (2006, p. 317) adverte que a isonomia não corresponde a princípio único na ordem jurídica. Destarte, a sua aplicação desacompanhada de outros mandamentos previstos pelo ordenamento jurídico pode levar o juiz à "tentação de não julgar, por sentir-se inapto a esta tarefa"

Recorde-se a que a igualdade no âmbito do direito à saúde, conforme Dallari e Maggio (2017, p. 64) é traduzida nas perspectivas formal e material, garantindo a última aquilo que é necessário para a restauração da condição de saúde de cada um. Isso se deve ao caráter multifacetário da saúde, que conforme leciona Dallari (2008, p. 12), depende “de características individuais, físicas e psicológicas, mas, também, do ambiente social e econômico, tanto daquele mais próximo das pessoas, quanto daquele que condiciona a vida dos Estados". Assim, ainda que não se manifestem na totalidade dos indivíduos, as doenças raras reclamam pela disponibilização dos respectivos tratamentos pelo sistema público de saúde, uma vez que as garantias de universalidade e de integralidade constitutivas do SUS pressupõem o alcance, na maior medida possível, de todos aqueles que necessitam das prestações de saúde mediante a oferta de serviços que atendam às carências de cada indivíduo.

Reconhecidas as limitações do princípio da universalidade, ao julgador incumbirá apreciar se o sujeito que requer determinada prestação de saúde que excede o conteúdo previsto pela relação oficial de medicamentos e de serviços de saúde disponibilizada pelo Estado tem condições de arcar com os tratamentos. Como a efetivação de direitos sociais por intermédio do Estado objetiva a redistribuição dos recursos em um sistema produtivo desigual (DUARTE, 2011), destinar os limitados recursos estatais para aqueles que possuem meios para tanto pode provocar o agravamento das desigualdades.

Por outro lado, quando determinado produto ou serviço é incorporado ao SUS, deve o magistrado verificar se houve (ou não) o cumprimento da política pública destinada a suprir a necessidade do paciente. Diante da existência de política pública instituída, porém insuficiente, o suprimento judicial da demanda será imperativo.

Os critérios estipulados devem observar os limites estabelecidos pela ordem jurídica para a preservação da saúde. A definição daquilo que é considerado como núcleo essencial do direito atua como parâmetro vinculante no processo decisório, uma vez que as prestações de saúde necessárias para a garantia da vida, como também aquelas consideradas de elevada 
essencialidade para a dignidade humana, devem ser deferidas em juízo, caso comprovada a ausência de disponibilização pelas vias administrativas. A aparente indefinição das prestações reputadas de alta essencialidade a serem garantidas no âmbito judicial não impede a atuação do magistrado. Pelo contrário, é nesse momento que se torna mais necessária a sua decisão, na medida em que ela expressa os contornos representativos da essência dos direitos na ordem jurídica. Por conseguinte, os níveis de imprecisão relacionados à temática são mitigados pelas noções de proteção insuficiente e de intervenção excessiva, construídos argumentativamente.

Por apresentarem, em geral, as doenças raras elevado potencial debilitante das funções motora e mental, a garantia de prestações que afetam sensivelmente a qualidade de vida dos seus pacientes revela algumas das funções elementares dos direitos sociais, como a inclusão social e a redução das desigualdades sociais. A garantia da vida atrelada à dimensão qualitativa da dignidade é a razão de ser do Estado e da ordem constitucional.

Em síntese, a garantia do direito à saúde manifesta o desafio de efetivação dos valores pactuados em sociedade, o que requer a interpretação da ordem jurídica sob a perspectiva da integridade dos comandos nela definidos.

\section{CONSIDERAÇÕES FINAIS}

A investigação realizada neste trabalho teve como objetivo iluminar as discussões travadas acerca do controle judicial de políticas públicas de saúde em matéria de doenças raras. Nesse contexto, a análise dos marcos normativos, doutrinários e jurisprudenciais propiciou reflexões no tocante aos princípios estruturantes da saúde pública no país, quais sejam, a universalidade e a integralidade. Observou-se que a criação da Política Nacional de Doenças Raras cumpre, apesar da existência de limites de ordem financeira, política e organizatória, com a ideia de integralidade do SUS.

Destacou-se, porém, que, apesar dos esforços empreendidos no tocante à ampliação da capacidade de atendimento dos pacientes com doenças raras e da incorporação de novas tecnologias à rede pública, a complexidade peculiar ao direito à saúde suscita a atuação do Poder Público mesmo para prestações que desbordam das prestações estipuladas nas políticas públicas. Como características específicas das doenças raras, identificaram-se alguns 
problemas relacionados à produção e ao acesso aos medicamentos para tais enfermidades, oportunidade em que foram destacados problemas de ordem ética, social e orçamentária.

Em busca do desenho do estado da arte da problemática, promoveu-se, outrossim, a análise da jurisprudência do Supremo Tribunal Federal. A pesquisa dos critérios utilizados nos julgados permitiu a reflexão quanto ao modo de atuação do Poder Judiciário na tutela do direito à saúde. Foram discutidos alguns dos critérios: existência de tratamentos disponibilizados pela rede pública; a consulta aos Protocolos Clínicos e Diretrizes Farmacêuticas; a capacidade econômica para o custeio dos tratamentos solicitados. Conclui-se que o uso destes parâmetros racionais nas decisões judiciais deve ter como limite a preservação do núcleo essencial do direito à saúde, o qual abarca a proteção da vida e da dignidade, traduzida nas prestações de elevada essencialidade.

\section{REFERÊNCIAS}

AITH, Fernando Mussa Abujamra. Direito à saúde e democracia sanitária: experiências brasileiras. Revista de Direito Sanitário, [s.l.], v. 15, n. 3, p.85-90, 14 abr. 2015. Universidade de Sao Paulo Sistema Integrado de Bibliotecas - SIBiUSP. http://dx.doi.org/10.11606/issn.2316-9044.v15i3p85-90. Disponível em: http://www.revistas.usp.br/rdisan/article/view/97328. Acesso em: 31 jan. 2019.

AITH, Fernando Mussa Abujamra. O direito à saúde e a política nacional de atenção integral aos portadores de doenças raras no Brasil. Jornal Brasileiro de economia da saúde: JBES, São Paulo, v. 6, n. supl. 1, p. 4-12, 2014. Disponível em: http://www.jbes.com.br/images/edicao-especial2014/jbes-especial01.pdf. Acesso em: 06 fev. 2019.

AITH, Fernando Mussa Abujamra et al. Os princípios da universalidade e integralidade do SUS sob a perspectiva da política de doenças raras e da incorporação tecnológica. Revista de Direito Sanitário, São Paulo, v. 15, n. 1, p.10-39, mar./jun. 2014. Disponível em: http://www.revistas.usp.br/rdisan/article/view/82804. Acesso em: 22 jan. 2019.

ALEXY, Robert. Teoria da Argumentação Jurídica: A teoria do discurso racional como teoria da fundamentação jurídica. Tradução de Zilda Hutchinson Schild Silva. 2. ed. São Paulo: Landy, 2005.

ALEXY, Robert. Teoria dos direitos fundamentais. Tradução de Virgílio Afonso da Silva. 2. ed. São Paulo: Malheiros, 2011. 
BRASIL. Comissão Nacional de Incorporação de Tecnologias no SUS. DOENÇAS RARAS: Governo, Especialistas e Pacientes juntos por um Sistema de Saúde Público inclusivo. 2019. Disponível em: http://conitec.gov.br/doencas-raras-governo-especialistas-e-pacientes-juntospor-um-sistema-de-saude-publico-inclusivo. Acesso em: 02 abr. 2019.

BRASIL. Comissão Nacional de Incorporação de Tecnologia no SUS. Priorização de Protocolos e Diretrizes Terapêuticas para Atenção Integral às Pessoas com Doenças Raras. Brasília: Ministério da Saúde, 2015. Disponível em: http://conitec.gov.br/images/Relatorios/2015/Relatrio_PCDT_DoenasRaras_CP_FINAL_142 _2015.pdf. Acesso em: 11 fev. 2019.

CIARLINI, Álvaro Luís de Araújo. Direito à saúde - paradigmas procedimentais e substanciais da Constituição. São Paulo, Saraiva, 2013.

DALLARI, Sueli Gandolfi. A construção do direito à saúde no Brasil. Revista de Direito Sanitário, São Paulo, v. 9, n. 3, p.9-34, 1 nov. 2008. Universidade de Sao Paulo Sistema Integrado de Bibliotecas - SIBiUSP. http://dx.doi.org/10.11606/issn.2316-9044.v9i3p9-34. Disponível em: http://www.revistas.usp.br/rdisan/article/view/13128. Acesso em: $17 \mathrm{dez}$. 2018.

DALLARI, Sueli Gandolfi. Fornecimento do medicamento pós-estudo em caso de doenças raras: conflito ético. Revista Bioética, [s.l.], v. 23, n. 2, p.256-266, ago. 2015. FapUNIFESP (SciELO). http://dx.doi.org/10.1590/1983-80422015232064. Disponível em:

http://www.scielo.br/scielo.php?script=sci_arttext\&pid=S1983-

$80422015000200256 \& \operatorname{lng}=$ pt\&tlng=pt. Acesso em: 14 fev. 2019.

DALLARI, Sueli Gandolfi; MAGGIO, Marcelo Paulo. A efetivação jurídico-política do direito à saúde no Supremo Tribunal Federal: a referência paradigmática da SL 47 -AGR/PE. Revista de Direito Sanitário, v. 17, n. 3, p. 58-76, 9 mar. 2017. Disponível em: http://www.revistas.usp.br/rdisan/article/view/127776. Acesso em 12 abr. 2019.

DUARTE, Luciana Gaspar Melquíades. A eficácia do direito social à saúde. Ética e Filosofia Política, Juiz de Fora, v. 1, n. 16, p.77-105, jun. 2013. Disponível em: http://www.ufjf.br/eticaefilosofia/files/2009/08/16_1_melquiades.pdf. Acesso em: 18 jan. 2019.

DUARTE, Luciana Gaspar Melquíades. Possibilidades e limites do controle judicial sobre as políticas públicas de saúde: um contributo para a dogmática do direito à saúde. Belo Horizonte: Fórum, 2011.

DWORKIN, Ronald. Levando os direitos a sério. Tradução e notas de Nelson Boeira. São Paulo: Martins Fontes, 2002. 
EURORDIS. Acerca das Doenças Raras. Disponível em: https://www.eurordis.org/ptpt/doencas-raras. Acesso em: 02 abr. 2019.

HUYARD, Caroline. How did uncommon disorders become 'rare diseases'? History of a boundary object. Sociology Of Health \& Illness, [s.1.], v. 31, n. 4, p.463-477, maio 2009. Wiley. http://dx.doi.org/10.1111/j.1467-9566.2008.01143.x. Disponível em: https://www.ncbi.nlm.nih.gov/pubmed/19397760. Acesso em: 27 mar. 2019.

KELSEN, Hans. Teoria pura do direito. Tradução de João Baptista Machado. 7 ed. São Paulo: Martins Fontes, 2006.

OLSEN, Ana Carolina Lopes. A eficácia dos direitos fundamentais sociais frente à reserva do possível. 2006. 378 f. Dissertação (Mestrado em Direito) - Universidade Federal do Paraná, Curitiba, 2006. Disponível em: http://dominiopublico.mec.gov.br/download/teste/arqs/cp007711.pdf. Acesso em: 18 jan. 2019.

PAIM, Jairnilson; TRAVASSOS, Cláudia; ALMEIDA, Célia; BAHIA, Lígia; MACINKO, James. O sistema de saúde brasileiro: história, avanços e desafios. The Lancet, [s.l]., p. 1131, 09 mai 2011. Disponível em: http://actbr.org.br/uploads/arquivo/925_brazil1.pdf. Acesso em: 19 jan. 2019.

SARLET, Ingo Wolfgang. A eficácia dos direitos fundamentais: uma teoria geral dos direitos fundamentais na perspectiva constitucional. 10. ed. Porto Alegre: Livraria do Advogado, 2011.

SARLET, Ingo Wolfgang; FIGUEIREDO, Maria Filchtiner. Reserva do possível, mínimo existencial e direito à saúde: algumas aproximações. In: SARLET, Ingo Wolfgang; TIMM, Luciano Benetti (org.).Direitos fundamentais: orçamento e reserva do possível. 2. ed. Porto Alegre: Livraria do Advogado, 2010. Cap. 1. p. 13-50.

TOLEDO, Cláudia. Justiciabilidade dos direitos fundamentais sociais e conflito de competências. In: TOLEDO, Cláudia. O pensamento de Robert Alexy como sistema. Rio de Janeiro: Gen, 2017. p. 278-292.

TOLEDO, Cláudia. Mínimo existencial - A Construção de um Conceito e seu Tratamento pela Jurisprudência Constitucional Brasileira e Alemã. Revista de Propriedade Intelectual, Direito Contemporâneo e Constituição, Aracaju, v. 11, n. 1, p.102-109, fev. 2017. Disponível em: http://pidcc.com.br/artigos/012017/062017.pdf. Acesso em: 28 jan. 2019.

U.S. FOOD AND DRUG ADMINISTRATION (Estados Unidos da América). Orphan Drug Act - Relevant Excerpts. Disponível em:

$<$ https://www.fda.gov/forindustry/developingproductsforrarediseasesconditions/howtoapplyfo rorphanproductdesignation/ucm364750.htm>. Acesso em: 02 abr. 2019. 
WORLD HEALTH ORGANIZATION. Constitution Of The World Health Organization, de 22 de julho de 1946. New York City, Disponível em:

http://apps.who.int/gb/bd/PDF/bd47/EN/constitution-en.pdf. Acesso em: 02 abr. 2019. 